\title{
Pengaruh Teknologi, Kepemimpinan Dan Kualitas Pelayanan Terhadap Perilaku Dan Kinerja Perusahaan (Studi Industri Percetakan di Kota Pekanbaru)
}

\author{
EKA FASSAROZI \\ Program Pascasarjana Universitas Riau \\ Jln. Pattimura Pekanbaru \\ E-mail : fassarozi@gmail.com
}

\begin{abstract}
This research is aimed at discovering the impact of technology oriented effect, leadership and quality service towards the competitiveness and performance of Printing Industry in Pekanbaru City. The employed sampling technique in this study is census method. The samples were 160 printing industry units which earn revenue above 50 million per year. The independence variable were the company's performance and its competitiveness. Meanwhile the dependence variables were technology oriented, leadership and service quality. The applied data analysis in this study was explanatory research by making use of warpPLS software. The findings observe that the leadership, service quality variables has brought impacts on the company's performance. It implies that the higher leadership and service quality, will result in the better company's performance. Furthermore, the company performance may influences the competitiveness, this indicates that the higher company's performance may generate higher competitiveness. Nevertheless, the technology oriented variable did not influence the company's performance. This means that the low and high of technology oriented may not result in changes towards the company's performance. The printing industry in Pekanbaru City therefore are expected to make the most of the latest technology.
\end{abstract}

Keywords: Technology Oriented, Leadership, Service Quality,Company Performance, Competitiveness

Pekanbaru sebagai salah satu kota yang di Indonesia yang sedang berkembang menjadi salah satu perkotaan yang industri percetakannya cukup berkembang. Berdasarkan data yang diperoleh Disperindag Kota Pekanbaru didapatkan bahwa industri percetakan dikota pekanbaru selalu mengalami pertumbuhan setiap tahunnya. Berikut tabel dibawah ini menunjukkan pertumbuhan industri percetakan dikota pekanbaru :

Perkembangan industri percetakan selalu mengalami pertumbuhan setiap tahunnya pada tahun 2011 industri percetakan dikota pekanbaru berjumlah 12 perusahaan, pada tahun 2012 menjadi 24 perusahaan, pada tahun 2013 menjadi 37 perusahaan, tahun 2014 menjadi 47 perusahaan dan pada tahun 2015 menjadi 53 perusahaan industri percetakan dikota pekanbaru.
Pada industri percetakan hasil produk dan harga hampir sama satu sama lainnya, sehingga industri percetakan yang ada dikota pekanbaru harus mempunyai daya unggul agar mampu bersaing. Tekhnologi yang mutakhir, kepemimpinan dan kualitas pelayanan menjadi pilihan agar industri percetakan menjadi unggul dalam persaingan.

Bisnis di era globalisasi saat ini sangat dituntut untuk dapat bertahan dengan persaingan yang sangat ketat, dimana perusahaan-perusahaan berusaha menghasilkan produk dengan kualitas yang sangat baik pula. Langkah-langkah yang dilakukan oleh perusahaan untuk memperbaiki kualitas produknya merupakan langkah-langkah yang harus didukung oleh manajemen serta sumberdaya yang berkualitas, karena inti dari perbaikan kualitas yang dilakukan perusahaan adalah memenuhi permintaan 
konsumen yang berorientasi pada kualitas, dan pelayanan (kecepatan, kemudahan, dan sebagainya).

Hal tersebut diatas inilah yang seharusnya menjadi perhatian para pelaku industri percetakan dikota pekanbaru yang harus segera diatasi, peningkatan kinerja industri percetakan menjadi suatu keharusan agar industri percetakan mampu bersaing dengan baik.

Berdasarkan hasil penelitian Chaston (1995) adapun yang menjadi faktor yang mempengaruhi kinerja perusahaan dalam menciptakan keunggulan bersaing yaitu kepemimpinan, kualitas pelayanan, dan tingkat orientasi teknologi.

Penelitian ini akan mengangkat tiga isu penting yang telah dijelaskan sebelumnya yang seharusnya diberi perhatian oleh perusahaan jika ingin meningkatkan kinerja perusahaannya dalam upaya menciptakan keunggulan bersaing, yaitu kepemimpinan, kualitas pelayanan dan tingkat orientasi teknologi.

Orientasi teknologi disini adalah kemampuan dan kemauan untuk mengambil teknologi sebagai suasana dalam operasionalisasi sehari-hari, dan menggunakannya dalam mengembangkan produk baru. Dengan mendasarkan pada penelitian dari Gatignon \& Xuereb (1997) indikator dari orientasi teknologi disini adalah kecepatan penggunaan dari teknologi baru, sikap terhadap pengembangan teknolgi baru.

Hasil-hasil penelitian terdahulu, baik secara eksplisit maupun implisit, mendukung hubungan positif antara variabel orientasi teknologi perusahaan dengan kinerja perusahaan. Seperti misalnya penelitian Gatignon \& Xuereb (1997) menunjukkan bahwa perusahaan yang berorientasi pada teknologi akan dapat meningkatkan kinerjanya. Sementara itu penelitian lain menunjukkan bahwa dampak penggunaan teknolgi baru akan meningkatkan kinerja (Hapsari,2004, (Hasan,2008),(Wulandari,2012), (Godhue \& Thomson, 2005), dapat mempercepat pengembangan produk baru gupta \&
Wilwmon (2006), respon pasar terhadap produk baru yang dihasilkan akan positif yang mana hal ini tentunya akan meningkatkan pernjualan produk perusahaan li \& calantone (2008) dalam perusahaan jasa, memiliki peran utama dalam mengurangi biaya.

Hasil-hasil penelitian terdahulu menunjukkan bahwa terdapat hubungan positif antara kualitas pelayanan yang diberikan oleh karyawan perusahaan terhadap kinerja perusahaan. Beberapa penelitian tersebut adalah hasil penelitian dari Andriani (2015) yang menyatakan terdapat pengaruh yang signifikan antara kualitas pelayanan terhadap kinerja perusahaan. Barker (2001) dan juga Baldauf et.al (2001) yang menyatakan bahwa memantabkan hubungan jangka panjang dengan konsumen dengan mempergunakan tenaga penjual dapat memberikan kepuasan konsumen melalui dorongan pada penjualan dan semangat pelayanan nampaknya akan membuat unit penjualan lebih efektif. Sementara itu penelitian lain menunjukkan bahwa peningkatan kualitas pelayanan sebagaimana yang diharapkan akan mempengaruhi kinerja organisasi Church (2005), kualitas pelayanan memiliki keterkaitan erat dengan peningkatan profibilitas perusahaan Chang \& Chen (2008)

Kepemimpinan mengandung arti kemampuan untuk mengilhami pihak lain. Kepemimpinan adalah berarti kemampuan secara intuitif memahami pikiran-pikiran orang lain yang tak terkatakan.Seorang pemimpin memiliki kemampuan untuk membawa pengikutnya bersama-sama dengan dia, mengilhami mereka, membuat keputusan-keputusan demi kepentingan mereka, dengan atau tanpa kerja sama mereka dan mengkomuinikasikan keputusan-keputusan mereka pada orang lain (Khaleele \& Pintab,2007).

Hubungan antara variabel kepemimpinan dan kinerja perusahaan didukung oleh hasil penelitian yang dilakukan oleh Krumwied \& Sheu (2008) 
yang menunjukkan bahwa kinerja perusahaan-perusahaan sebenarnya juga dipengaruhi oleh kurangnya dukungan dari pimpinan.

Tujuan dari strategi kompetitif adalah pencapaian keunggulan bersaing yang berkelanjutan dengan meningkatkan kinerja perusahaan. Keunggulan yang berkelanjutan dicapai ketika keunggulan tersebut dapat bertahan dari erosi atau perilaku pesaing (Porter,2008). dengan kata lain keterampilan dan sumberdaya y ang mendasari dari keunggulan kompetitif bisnis harus mampu bertahan dari duplikasi perusahaan lain (Barney,2007).Menurut Barney (2007), terdapat 4 (empat) esensi persyaratan dari sumberdaya dan keterampilan agar dapat dikatakan sebagai sumberdaya dari keunggulan bersaing adalah : haruslah bernilai, jarang atau unik dari perusahaan lainnya, bentuknya untuk dapat dilakukan peniruan sangatlah sulit karena produk/jasa tersebut sempurna serta tidak mudah untuk dapat digantikan dengan sumberdaya yang lainnya (Barney 2007; Coyne,2006).

Berkaitan antara pengaruh kinerja perusahaan terhadap keunggulan bersaing, pengaruh kinerja perusahaan terhadap keunggulan bersaing dapat tercapai ketika kemampuan manajemen dan menggunakan kreasi dan mengimplentasikan strategi agar tahan pada keunggulan yang banyak terjadi peniruan, mampu menciptakan faktor hambatan dalam jangka waktu yang lama.(Bharawaj, Varadarajan dan Fahy,2006; Grant,2006; Mahoney dan Pandian,2007; Rumelt,2007).

\section{METODE}

Penelitian ini dimulai pada Bulan Agustus 2015, sedangkan lokasi penelitian adalah industri percetakan yang ada di kota pekanbaru. Populasi yang digunakan adalah seluruh industri percetakan yang ada dikota pekanbaru yang berjumlah 172. Adapun yang menjadi sampel pada penelitian kali ini adalah industri percetakan yang mempunyai nilai investasi diatas $\mathrm{Rp}$. 50.000 .000 yang terdaftar di
DISPERINDAG kota pekanbaru yang berjumlah 160 unit usaha percetakan.

Penelitian ini menggunakan teknik Partial Least Square. Partial Least Square (PLS) pertama kali dikembangkan oleh Herman Wold, beliau adalah guru dari Karl Joreskog (yang mengembangkan SEM). Model ini dikembangkan sebagai alternatif untuk situasi di mana teorinya lemah dan atau indikator yang tersedia tidak memenuhi model pengukuran reflesif. Wold menyebutkan PLS sebagai "soft modeling". PLS merupakan metode analisis yang powerful karena dapat diterapkan pada semua skala data, tidak membutuhkan banyak asumsi dan ukuran sampel tidak harus besar. PLS selain dapat digunakan sebagai konfirmasi teori juga dapat digunakan untuk membangun

Di dalam PLS variabel latent bisa berupa hasil pencerminan indikatornya, diistilahkan dengan indikator refleksif (refletive indicator). Di samping itu, juga bisa konstruk dibentuk (formatif) oleh indikatornya, diistilahkan dengan indikator formatif (formative indicator).

\section{HASIL}

Pengujian inner model (structural model) pada intinya menguji hipotesis dalam penelitian. Pengujian hipotesis dilakukan dengan uji t (T-Statistic) pada masing-masing jalur pengaruh langsung secara parsial. Hasil analisis secara lengkap, terdapat dalam hasil analisis WarpPLS.

Tabel 1 Hasil Pengujian Hipotesis dalam Inner Model dalam WarpPLS

\begin{tabular}{|l|c|c|c|}
\hline \hline \multicolumn{1}{|c|}{ Hubungan } & $\begin{array}{c}\text { Koefisien } \\
\text { Jalur }\end{array}$ & $\begin{array}{c}\boldsymbol{p} \text { - } \\
\text { value }\end{array}$ & Keterangan \\
\hline $\begin{array}{l}\text { Orientasi Teknologi } \rightarrow \\
\text { Kinerja Perusahaan }\end{array}$ & 0.072 & 0.184 & $\begin{array}{c}\text { Non } \\
\text { Signifikan }\end{array}$ \\
\hline $\begin{array}{l}\text { Kepemimpinan } \rightarrow \\
\text { Kinerja Perusahaan }\end{array}$ & 0.591 & $\begin{array}{c}< \\
0.001\end{array}$ & Signifikan \\
\hline $\begin{array}{l}\text { Kualitas Pelayanan } \rightarrow \\
\text { Kinerja Perusahaan }\end{array}$ & 0.259 & $\begin{array}{c}< \\
0.001\end{array}$ & Signifikan \\
\hline $\begin{array}{l}\text { Kinerja Perusahaan } \rightarrow \\
\text { Keunggulan Bersaing }\end{array}$ & 0.321 & $\begin{array}{c}< \\
0.001\end{array}$ & Signifikan \\
\hline
\end{tabular}

Sumber: Data Sekunder Diolah (2016) 


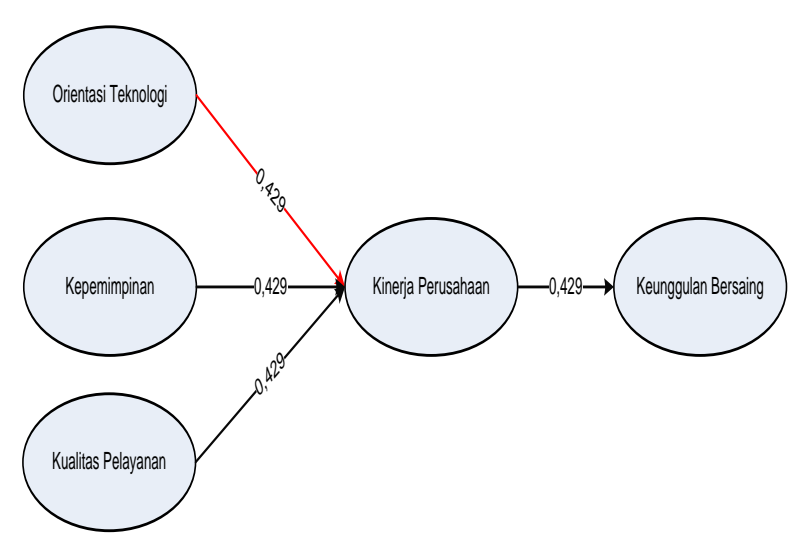

Gambar 1.

Hasil Pengujian Hipotesis dalam Inner Model WarpPLS

\section{PEMBAHASAN}

Berdasarakan pengujian analaisa WarpPLS pada tabel dan grafik, pada pengujian pengaruh langsung antara orientasi teknologi terhadap kinerja perusahaan, diperoleh nilai koefisien inner weight sebesar 0.072 , dengan $p$-value sebesar 0.184. Karena $p$-value $>0.05$, maka tidak terdapat pengaruh langsung yang signifikan antara orientasi teknologi terhadap kinerja perusahaan. Hal ini mengindikasikan bahwa tinggi rendahnya orientasi teknologi, tidak akan mengakibatkan perubahan pada tinggi rendahnya kinerja perusahaan.

Pada pengujian pengaruh langsung antara kepemimpinan terhadap kinerja perusahaan, diperoleh nilai koefisien inner weight sebesar 0.591 , dengan $p$-value sebesar $<0.001$. Karena p-value < 0.05, maka terdapat pengaruh langsung yang signifikan antara kepemimpinan terhadap kinerja perusahaan. Mengingat koefisien inner weight bertanda positif, mengindikasikan bahwa hubungan keduanya positif. Artinya, semakin tinggi kepemimpinan, akan mengakibatkan semakin tinggi kinerja perusahaan.

Pada pengujian pengaruh langsung antara kualitas pelayanan terhadap kinerja perusahaan, diperoleh nilai koefisien inner weight sebesar 0.259 , dengan $p$-value sebesar $<0.001$. Karena p-value $<0.05$, maka terdapat pengaruh langsung yang signifikan antara kualitas pelayanan terhadap kinerja perusahaan. Mengingat koefisien inner weight bertanda positif, mengindikasikan bahwa hubungan keduanya positif. Artinya, semakin tinggi kualitas pelayanan, akan mengakibatkan semakin tinggi kinerja perusahaan.

Pada pengujian pengaruh langsung antara kinerja perusahaan terhadap keunggulan bersaing, diperoleh nilai koefisien inner weight sebesar 0.321, dengan $p$-value sebesar $<0.001$. Karena $p$ value $<0.05$, maka terdapat pengaruh langsung yang signifikan antara kinerja perusahaan terhadap keunggulan bersaing. Mengingat koefisien inner weight bertanda positif, mengindikasikan bahwa hubungan keduanya positif. Artinya, semakin tinggi kinerja perusahaan, akan mengakibatkan semakin tinggi keunggulan bersaing.

\section{SIMPULAN}

Berdasarkan hasil analisis, diperoleh kesimpulan sebagai berikut: Mengingat koefisien inner weight bertanda negatif, mengindikasikan bahwa terdapat hubungan negatif antara orientasi tekhnologi terhadap kinerja perusahaan. Sehingga dapat disimpulkan bahwa tidak terdapat pengaruh yang signifikan antara orientasi teknologi terhadap kinerja perusahaan. Hal ini mengindikasikan bahwa tinggi rendahnya orientasi teknologi, tidak akan mengakibatkan perubahan pada tinggi rendahnya kinerja perusahaan.

Terdapat pengaruh langsung yang signifikan antara kepemimpinan terhadap kinerja perusahaan. Mengingat koefisien inner weight bertanda positif, mengindikasikan bahwa hubungan keduanya positif. Artinya, semakin tinggi kepemimpinan, akan mengakibatkan semakin tinggi kinerja perusahaan.

Terdapat pengaruh langsung yang signifikan antara kualitas pelayanan terhadap kinerja perusahaan. Mengingat koefisien inner weight bertanda positif, mengindikasikan bahwa hubungan keduanya positif. Artinya, semakin tinggi kualitas pelayanan, akan mengakibatkan semakin tinggi kinerja perusahaan. 
Terdapat pengaruh langsung yang signifikan antara kinerja perusahaan terhadap keunggulan bersaing. Mengingat koefisien inner weight bertanda positif, mengindikasikan bahwa hubungan keduanya positif. Artinya, semakin tinggi kinerja perusahaan, akan mengakibatkan semakin tinggi keunggulan bersaing.

\section{DAFTAR RUJUKAN}

Adi Sismanto, 2006. "Analisis Pengaruh Orientasi Pembelajaran, Orientasi Pasar, dan Inovasi Terhadap Keunggulan Bersaing Untuk Meningkatkan Kinerja Pemasaran". Universitas Diponegoro, Semarang.

Askok K.Gupta, S.P.Raj, dan David Wilemon 2006, “A Model For Studying $R \& D$ Marketing Interface in The Product Innovation Process", Journal of Marketing, Vol. April, Hal 7-17.

Buachari Alma, 2010. "Metode dan Teknis Menyusun Tesis". Alfabeta, Bandung

Cahyono, Bambang Tri, 2010. Melawan Ekonomi Terorisme, Penerbit PT Strategic Spiritual Quotient International, Jakarta,.

Cahyono, Budi and Yuyetta, Etna Nurafri. 2011. Pengaruh corporate social responsibility terhadap kinerja perusahaan dengan kepemilikan asing sebagai variabel moderating (studi empiris pada perusahaan manufaktur yang terdaftar di bursa efek indonesia). Undergraduate thesis, universitas diponegoro

Carton, R.B. 2007. Measuring Organizational Performance: An Exploratory Study. Athens, Georgia: The University of Georgia
Dinda Estika Asmarani, 2006. "Analisis Pengaruh Perencanaan Strategi Terhadap Kinerja Perusahaan Dalam Upaya Menciptakan Keungulan Bersaing, Studi Empiris Pada Industri Kecil Menengah di Troso, Jepara". Universitas Diponegoro, Semarang.

Ghozali, Iman, 2008. "Structural Equation Modeling : Model Alternatif dengan Partial Least Square". Universital Diponegoro, Semarang

Goodhue, D.I dan Thompson. R. L. 2005. "Task -Technology and Individual Performance”. Mis Quarterly, Juni 213-236

Hadjimanolis, Athanasios, 2010, "An Investigation of Innovation antencendent in Small Firm in the Context of small Developing Country”,R\&D Management, Vol 30

Hatmoko, Tony. 2006.Pengaruh Kepuasan Kerja Terhadap Komitmen Organisasi Dan Pembedaannya Terhadap Karakteristik Demografik (Studi Kasus Di PDAM Kabupaten Karanganyar). Tesis Program Pascasarjana Universitas Sebelas Maret Surakarta.

Hitt M.A, \& Keats De Marie. 2008. Academy of Management Executive: The Thingking Manager. NY: Academic of Management.

Hitt/ireland/hoskisson, Michael A. Hitt, R. Duane Ireland, Robert E. Hoskisson. 2007.Strategic Management Competitiveness and Globalization; [concepts]. Thomson South-Western, 
Ibrahim Ingga, 2008. "Pengaruh Lingkungan Eksternal, Lingkungan Internal, Strategi Kempemimpinan Biaya, Strategi Diferensiasi Terhadap Nilai Pelanggan dan Keunggulan Bersaing". Universitas Brawijaya, Malang.

Jahanshahi, A. A., Rezaie, M., Nawaser, K., Ranjbar, V., \& Pitamber, B. K. 2012. Analyzing the Effect of Electronic Commerce on Organizational Performance : Evidence from Small and Medium Enterprises. African Journal of Business Management.

Jay H. Heizer, Barry Render. 2013 .Operations

Management: Sustainability and Supply Chain Management. Pearson Education -796 halaman

John C. Mowen, Michael Minor. 2006. Consumer BehavioR. Cram101 Incorporated,

Juliansyah Noor, 2013. "Analisa Data Penelitian Ekonomi \& Manajemen". Penerbit Gramedia Widiasarana, Jakarta.

Koufteros, Xenophon, 2006. "Product Development practices and performance: A Structural equation modeling-based multi-group analysis", international journal of production economics 103 , no. 1

Li, S., Ragu-Nathan,B., Ragu-Nathan, T.S. \& Subba Rao, S. (2006). "The Impact of Supply Chain Management Practise on Competitive Advantage and Organizational performance," Omega, 34

Moeheriono.2012, Pengukuran kinerja berbasis kinerja, Edisi revisi. Jakarta: PT. Raja Grafindo Persada

Jurnal Daya Saing
Mulyadi. 2007. Sistem Terpadu Pengelolaan Kinerja Personel Berbasis Balanced Scorecard. Yogyakarta: STIM YKPN.

Nabaga, Tameng. "Pengaruh Orientasi Pembelajaran, Lingkungan Internal, Dan Perilaku Wirausaha Terhadap Kinerja Perusahaan Dan Keunggulan Bersaing (Studi Empiris Pada Local Bussines Development PT. CPI - Sumatera Operation)". Tesis Universitas Riau. Pekanbaru.

Pitts R., and Lei, D. 2006. Strategic Management:Building and sustaining competitive advantage. South-Western: Thompson

Rahayu Puji Suci, 2009. "Peningkatan Kinerja Melalui Orientasi Kewirausahaan, Kemampuan Manajemen, dan Strategi Bisnis, Studi Pada Industry Kecil Menengah Border Di Jawa Timur". Jurnal +-Manajemen dan kewirausahaan. Vol. 11, No.1, p 46-54

Ravi Aron and Eric K. Clemons, 2001. "Achieving the Optimal Balance between Investment In Quality and Investment in SelfPromotion", Journal of Management Information Systems 18 (2): pp. 65-88.

Robert B. Carton, Charles W. Hofer Edward Elgar.2006. Measuring Organizational

Performance: Metrics for Entrepreneurship and Strategic. Management Research Publishing,2006 .

Robert G. Cooper, Elko J. Kleinschmidt.2011. New Products: The Key Factors in Success. Marketing Classics Press.

p.ISSN: $2407-800 X \quad$ e.ISSN: $2541-4356$ 
Singgih Santoso, 2007. "Structural Equation Modeling, Konsep dan Aplikasi Dengan AMOS". Elex Media Komputindo, Jakarta.

Solihin, Ismail, 2012. "Manajemen Strategik". Penerbit Erlangga, Jakarta

Syafar,A.W. 2004. "Membangun Daya Saing Daerah melalui Kompetensi Khas (Distinctive Competence) Berbasis Komoditi Unggulan" Usahawan No 03, TH XXXIII - Maret, hlm.311
Veithzal Rivai, 2008, Manajemen Sumvo, Daya Manusia untuk Perusahaan, Bandung: PT. Remaja Rosda Karya.

Voss, Z. G \& Voss, G.B. 2008. The effects of slack resources and eviromental threat on product exploration and exploitation. Academy of management journal,51, 147-164

Wahyudiono, 2007, Pengaruh Orientasi Pasar dan Orientasi Teknologi Terhadap Inovasi Berkelanjutan dan Kinerja Perusahaan Cunsomer Goods di Surabaya, Jurnal Sains dan Pemasaran 